\title{
Fecal Lactoferrin and Other Putative Fecal Biomarkers in Crohn's Disease: Do They Still Have a Potential Clinical Role?
}

\author{
Filippo Vernia ${ }^{a}$ Angelo Viscido ${ }^{a}$ Mirko Di Ruscio ${ }^{b}$ Gianpiero Stefanelli ${ }^{a}$ \\ Marco Valvano ${ }^{a}$ Giovanni Latella ${ }^{a}$ \\ aGastroenterology Unit, Department of Life, Health and Environmental Sciences, University of L'Aquila, Piazza S. \\ Tommasi, L'Aquila, Italy; 'bIBD Unit of IRCCS Ospedale Sacro Cuore - Don Calabria, Verona, Italy
}

\section{Keywords}

Fecal lactoferrin · Fecal biomarkers · Fecal markers · Crohn's disease $\cdot$ Inflammatory bowel diseases

\begin{abstract}
Introduction: The need for noninvasive markers of disease activity is mandatory in the assessment of Crohn's disease (CD). The most widely fecal biomarker in $C D$, despite several limits, is fecal calprotectin. This review aims to elucidate the role, if any, of all other fecal biomarkers, as alternative tools for assessing clinical and endoscopic disease activity, and predict capsule endoscopy findings, response to therapy, disease relapse, and postoperative recurrence. These fecal biomarkers included lactoferrin, S100A12, high mobility group box 1, neopterin, polymorphonuclear neutrophil elastase, fecal hemoglobin, alpha1-antitrypsin, lysozyme, human beta-defensin-2, neutrophil gelatinase-associated lipocalin, matrix metalloproteinase-9, chitinase 3-like-1, M2-pyruvate kinase, myeloperoxidase, and eosinophil proteins. Methods: A systematic electronic search in the medical literature was performed up to April 2020. Seventy eligible studies were identified out of 859 citations. Data were grouped according to the assessment of clinical and endo-
\end{abstract}

scopic disease activity, capsule endoscopy findings, response to therapy, prediction of relapse, and postoperative recurrence. Results: The overall correlation between lactoferrin and clinical indexes is poor, while performance is good with endoscopic scores. Lactoferrin seems to represent a reasonably good surrogate marker of response to therapy and to be potentially useful in identifying patients at high risk for endoscopic relapse or postoperative recurrence. The evaluation of the performance of all other fecal markers is limited by the lack of adequate data. Conclusions: None of the fecal markers so far represents an acceptable alternative to calprotectin in clinical practice. Fecal lactoferrin is the only possible exception, but a more extensive investigation is still required.

() 2021 S. Karger AG, Basel

\section{Introduction}

Crohn's disease (CD) symptoms are often nonspecific. Therefore, noninvasive markers of disease activity are often employed to optimize invasive procedures, such as colonoscopy, or expansive imaging techniques. The most widely used fecal biomarker in inflammatory bowel disease (IBD) is fecal calprotectin. However, the best thresh-
(C) 2021 S. Karger AG, Basel

Karger
Correspondence to:

Giovanni Latella, giolatel@tin.it 
old value to monitor disease activity, as well as the most effective interval between measurements, is still ill-defined, more so in CD than in ulcerative colitis (UC). This results in high variability of data reported in the literature and wide variations of sensitivity $(36-100 \%)$ and specificity $(25-100 \%)$ [1].

Several studies have been carried out to overcome these limits without reaching solid conclusions. Evaluating the performance of alternative fecal biomarkers may thus help to assess if and in which instances they could perform better than FC.

Alternative biomarkers are fecal lactoferrin (FL), S100A12, high mobility group box 1 (HMGB1), neopterin, polymorphonuclear neutrophil elastase (PMN-e), fecal hemoglobin, alpha1-antitrypsin (AAT), lysozyme (Lys), human beta-defensin-2 (HBD2), neutrophil gelatinase-associated lipocalin (NGAL), matrix metalloproteinase 9 (MMP9), chitinase 3-like-1 (CHI3L1), M2-pyruvate kinase (M2-PK), myeloperoxidase (MPO), and fecal eosinophil proteins, but their potential role in $\mathrm{CD}$ has not been evaluated in detail, except for FL $[2,3]$. The present study critically reviewed the available information, to elucidate the role of FL and other fecal biomarkers, besides FC, as tools for evaluating clinical and endoscopic disease activity, and predict capsule endoscopy (CE) findings, response to therapy, disease relapse, and postoperative recurrence (POR), in CD.

\section{Methods and Search Strategy}

A systematic electronic search of the English literature up to April 2020 was performed using Medline (EBSCO host), Embase, and the Cochrane Library. The search strategy used a combination of Medical Subject Headings and keywords as follows: "Inflammatory Bowel Disease," "IBD," "Crohn's/Crohns/Crohn disease," "fecal/faecal lactoferrin," "fecal/faecal markers," "fecal/faecal biomarkers," "S100A12," "high mobility group box 1," "HMGB1," "neopterin," "polymorphonuclear neutrophil elastase," "PMN-e," "fecal/faecal haemoglobin," "alpha1-antitrypsin," "AAT," "lysozyme," "Lys," "human beta-defensin-2," "HBD2," "neutrophil gelatinase-associated lipocalin," "NGAL," "matrix metalloproteinase 9," "MMP9," “chitinase 3-like-1," "CHI3L1," "M2-pyruvate kinase," "M2-PK," "myeloperoxidase," "MPO," "faecal eosinophil proteins," "relapse," "recurrence," " post-operative recurrence," "endoscopy," and "capsule endoscopy."

Four authors (F.V., M.D.R., G.S., and G.L.) screened the data and identified relevant articles. Additional studies were selected after a manual review of the reference list of the identified studies and review articles. All data were recorded independently by the reviewers in separate databases and were compared at the end of the reviewing process to limit selection bias. Any discrepancy was resolved by consensus, referring to the original articles.
Only articles written in English that analyzed human stool samples were included. In vitro studies, animal studies, studies on blood/serum samples, and abstracts were excluded. Search results were not limited to any geographical area.

Out of 859 citations, 70 eligible studies were identified. The reason for the exclusion of all other articles is reported in the PRISMA diagram (shown in Fig. 1). The PRISMA checklist is available in online supplementary Table 1 (for all online suppl. material, see www.karger.com/doi/10.1159/000518419).

When available, data on sensitivity, specificity, and accuracy for each cutoff were extracted and reported. Data were grouped according to the assessment of clinical and endoscopic disease activity, CE findings, response to therapy, prediction of relapse, and POR.

\section{Stool Markers and Assessment of Clinical Activity}

$\mathrm{CD}$ is a chronic, relapsing, and remitting condition that requires lifelong monitoring of disease activity. In the clinical setting, the assessment of activity is usually based on the combined monitoring of systemic inflammatory markers and symptoms. Systemic inflammatory markers are nonspecific, and symptoms are subjective and correlate poorly with endoscopic activity [4]. Thus, ileo-colonoscopy remains the gold standard to monitor $\mathrm{CD}$ but is often useless in small bowel disease. Moreover, being invasive is often refused by patients, more so with long-standing disease and in clinical remission. Hence, there is a need for substitute markers of disease activity.

Studies on FL markedly differ for the definition of disease activity, the clinical score used, study design, and FL cutoff levels (Table 1), making difficult the comparison of the results. Moreover, the series are small, as only 2 studies include $>100$ patients.

Kane et al. [5] evaluated FL in patients with active disease, reporting suboptimal accuracy (cutoff $12.8 \mu \mathrm{g} / \mathrm{g}$; sensibility $74.4 \%$, specificity $44.4 \%$ ). The study however has been carried out in few patients, and the definition of active disease was based on a modified Harvey-Bradshaw Index (HBI). Interestingly, no differences in FL were reported with disease location [5].

A pediatric study showed that FL levels were comparable to erythrocyte sedimentation rate in detecting active disease defined by the Pediatric Crohn's Disease Activity Index (PCDAI) and the HBI [6]. Conversely, other small cohort studies reported that levels of FL were significantly higher in patients with Crohn's Disease Activity Index (CDAI) $>150$ than in those in remission [7-9]. The correlation between FL and clinical indexes is overall poor (Table 1), except for the study of Karczewski et al. [10] who reported a moderate correlation between FL and CDAI $(r=0.675, p<0.05)$. 


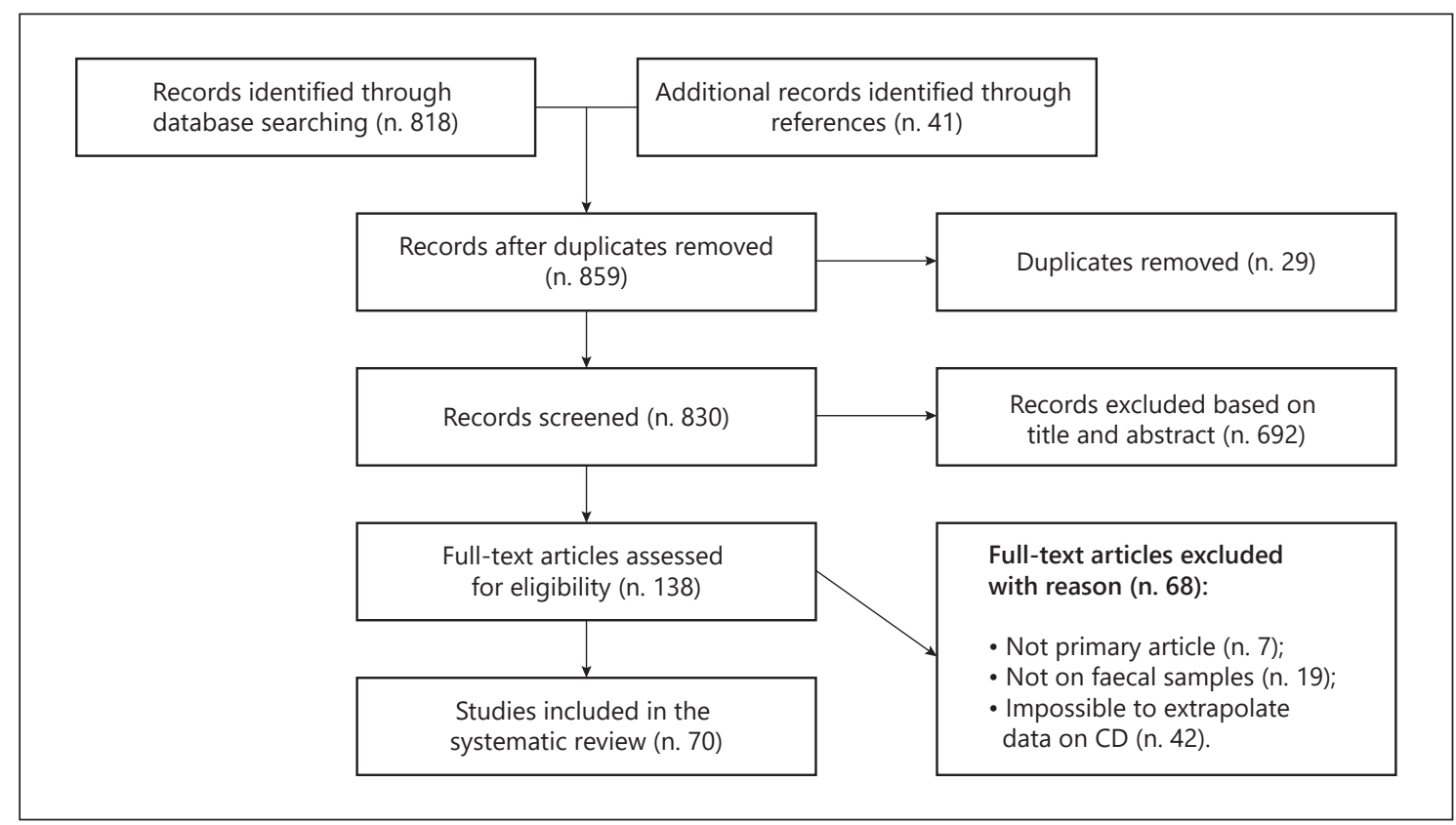

Fig. 1. PRISMA diagram reports the reasons for the exclusion of the articles. CD, Crohn's disease.

In a recent meta-analysis, the FL-pooled sensitivity and specificity values for assessing $\mathrm{CD}$ activity were 0.82 (95\% CI, 0.73-0.88) and 0.71 (95\% CI, 0.63-0.78), respectively [2]. As reported for FC, FL shows lower values in patients with isolated ileal versus colonic involvement but data are scarce, and no clear conclusion may be drawn [11]. Considering other fecal markers of inflammation, S100A12 levels correlate with pediatric CDAI, in pancolitis but not in small bowel disease or less extensive colonic disease [12]. Conversely, a good correlation between disease activity and FC levels was reported in noncontinuous colonic involvement, but not in pancolitis, suggesting that the 2 proteins might be induced/modulated by different factors [13].

The only study carried out in adults did not find correlations between S100A12 and CDAI, despite a statistically significant association with histological inflammation $(r=0.440 ; p<0.01)$ [14]. Fecal neopterin levels were increased in both active and inactive CD (96.0 ng/g and $87.2 \mathrm{ng} / \mathrm{g}$, respectively) when compared to the controls $[15,16]$. They also showed a significant $(p<0.001)$ correlation with the HBI, but far from optimal correlation coefficient $(r=0.41)$ [16].

PMN-e, NGAL, CHI3L1, M2-PK, Lys, ECP, and EPX all correlate with active disease, in adults [17-28]. The same is true for S100A12 and CHI3L1 in children [12,
29-32]. The correlation coefficient with clinical scores showed wide variations in most series (Table 1). The best correlations were reported by Adeyemi et al. [17] in adult patients (PMN-e and CDAI; $r=0.78, p<0.05)$ and Roszak et al. [30] in children (M2-PK and PCDAI; $r=0.820, p<$ 0.05). Conflicting results concern AAT [18, 31, 33-35] and M2-PK in pediatric cohorts [36]. HBD2 does not provide useful information on disease activity [37].

\section{Stool Markers and Endoscopic Activity}

Mucosal healing is associated with reduced risk of hospitalization, need for steroids and surgery, and a better quality of life and represents a primary therapeutic goal in CD patients. As far as stool markers are concerned, no agreement has been reached on the optimal thresholdlevel correlating FL and endoscopic activity. Most authors suggested a $7.25 \mu \mathrm{g} / \mathrm{g}$ threshold, with $71-93.2 \%$ sensitivity and $76.5-83 \%$ specificity $[9,11,38]$. Better sensitivity, specificity, positive predictive value (PPV), and negative predictive value (NPV) $(66 \%, 92 \%, 94 \%$, and $59 \%$, respectively) were reported by Sipponen et al. [39] using a threshold level of $10 \mu \mathrm{g} / \mathrm{g}$ in a cohort of $77 \mathrm{CD}$ patients. It was thus suggested that FL provides higher accuracy in predicting endoscopic activity as compared to 
Table 1. Fecal markers and assessment of disease activity in $C D$, according to clinical scores

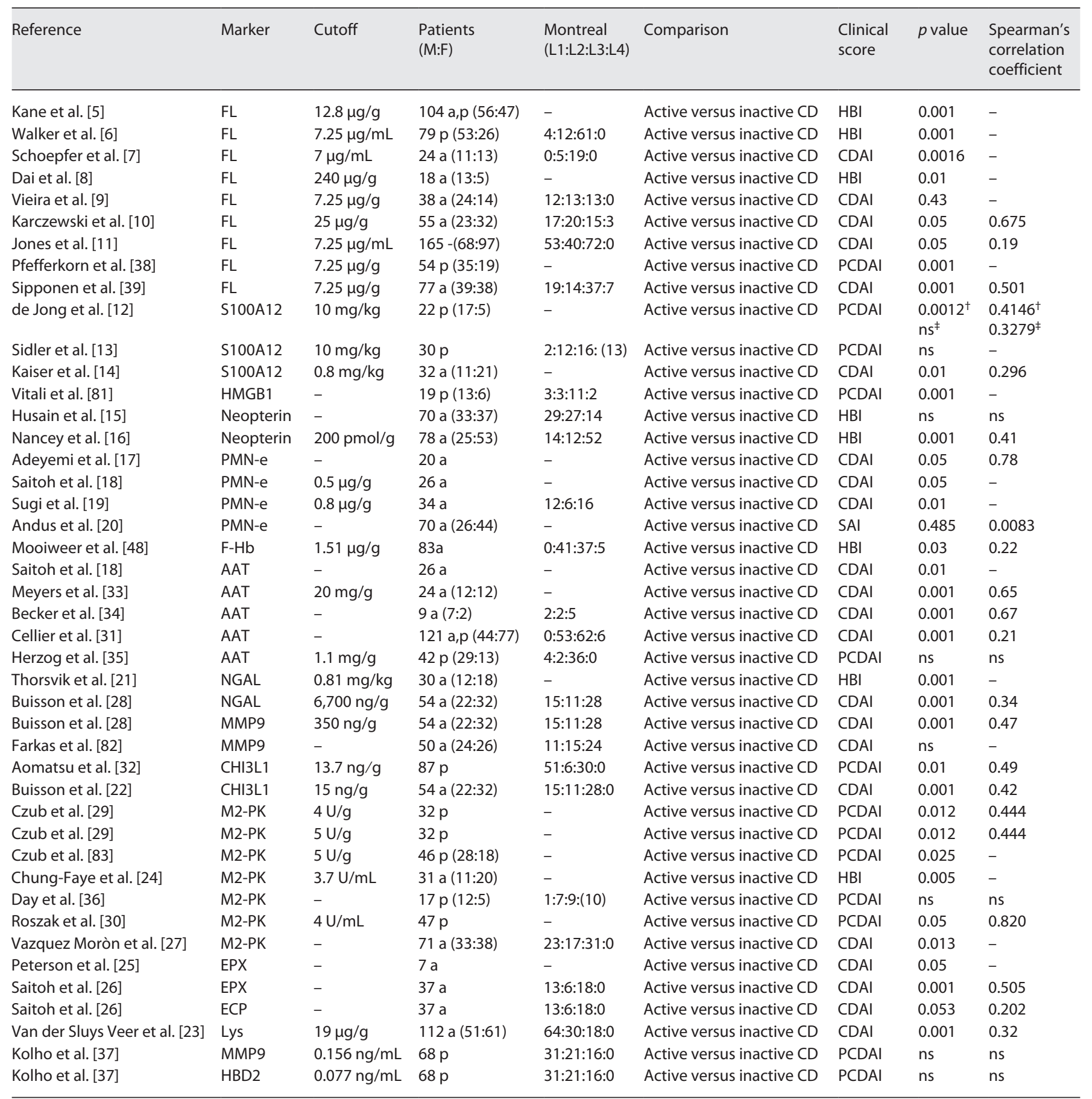

FL, fecal lactoferrin; HMGB1, high mobility group box 1; PMN-e, polymorphonuclear neutrophil elastase; F-Hb, fecal hemoglobin; AAT, alpha 1-antitrypsin; NGAL, neutrophil gelatinase-associated lipocalin; MMP9, matrix metalloproteinase 9; CHI3L1, chitinase 3-like-1; M2-PK, M2-pyruvate kinase; ECP, eosinophil cationic protein; EPX, eosinophil protein X; Lys, lysozyme; HBD2, human beta-defensin-2; a, adult patients; p, pediatric patients; PCDAl, Pediatric Crohn's Disease Activity Index; CDAl, Crohn's Disease Activity Index; HBI, Harvey-Bradshaw Index; -, not reported; CD, Crohn's disease. When expressed in brackets, the L4 behavior describes a concomitant involvement of the upper GI. ${ }^{\dagger}$ Pancolitis. ${ }^{\ddagger}$ Noncontinuous colonic disease; ns: nonsignificant. 
CDAI or C-reactive protein [39]. According to a recent meta-analysis, the optimal cutoff point was $7.25 \mu \mathrm{g} / \mathrm{mL}$, corresponding to $82 \%$ sensitivity ( $95 \%$ CI, $73 \%-88 \%$ ) and $79 \%$ specificity (95\% CI, $62 \%-89 \%$ ) for the detection of endoscopic activity [40].

Vieira et al. [9] evaluated the endoscopic activity of 38 adult CD patients with Crohn's Disease Endoscopic Index of Severity (CDEIS) and found a significant correlation with FL ( $p=0.0001)$, the sensitivity of $93.2 \%$, specificity of $76.5 \%$, PPV of $83.7 \%$, and NPV of $89.7 \%$ with a cutoff of $7 \mu \mathrm{g} / \mathrm{mL}$. Interestingly, one study reported that in ileal disease, fecal calprotectin failed to correlate with CDEIS ( $r=0.316, p=0.151$ ), opposite to a significant correlation of lactoferrin $(r=0.678, p=0.001)$ [39]. Unfortunately, these results were not confirmed by the same author in a different cohort, using a simple endoscopic score for Crohn's disease (SES-CD) as reference [41].

The usefulness of FL in the prediction of endoscopically active disease in the colon has been recently confirmed in a study on 101 patients, reporting $84.6 \%$ sensitivity and $60.5 \%$ specificity ( $p=0.0347$ ), with PPV of $42 \%$ and NPV of $92 \%$ at a concentration of $145.82 \mu \mathrm{g} / \mathrm{mL}$ [42]. A good correlation of FL with endoscopic scores was shown only in 5 out of 15 studies (Table 2) [9, 10, 39, 41, 43]. Unfortunately, the correlation between FL and endoscopic scores was not assessed in the 2 published metaanalyses $[2,40]$.

Interestingly, a small study by D'Incà et al. [44] did not show a significant correlation of FL with endoscopic activity, but only with histological inflammation $(p=0.009)$. A correlation with SES-CD as well as with histology was instead reported by Sipponen et al. [41], in those patients with colonic or ileocolonic CD $(r=0.543 ; p<0.001)$.

An overall evaluation of data suggests that FL represents a possible indicator of mucosal healing. The use of different criteria of endoscopic activity supports the need for further studies to define the issue. As reported for fecal calprotectin, also FL seems to perform poorly in ileal CD. However, due to the small number of patients enrolled, as only 3 studies included $>100$ patients, the issue is still open.

Among other markers, HMGB1, neopterin, fecal immunochemical test, NGAL, CHI3L1, and M2-PK effectively discriminated active endoscopic inflammation from the inactive disease $[16,21,22,27,32,45-48]$. A moderate correlation between CHI3L1 and endoscopic scores (SES-CD and CDEIS) was found in both pediatric and adult $C D$ patients $[22,32]$. According to a recent study, NGAL and MMP9 are effective in detecting ileal disease, showing a better correlation coefficient than FC [28]. The effectiveness of neopterin and CHI3L1 was comparable to FC $[16,22]$. Conversely, FC is superior to fecal immunochemical test and M2-PK, especially in patients with terminal ileum disease $[27,47,48]$.

Correlation of fecal markers with both SES-CD and histological inflammation was recently reported for fecal HMGB1 only, with an accuracy comparable with that of FC [46]. All other putative fecal markers did not differentiate active versus inactive endoscopic lesions (Table 2).

\section{Stool Markers and Capsule Endoscopy}

According to the French EPIMED, 20.6\% of patients with $C D$ have a disease limited to the small bowel [49]. In these patients, CE represents an effective diagnostic option when the clinical suspicion of $\mathrm{CD}$ remains high despite negative endoscopy and cross-imaging findings [50].

The role of fecal markers as a predictor of CE findings is supported by limited evidence. A small study reported a $41 \%$ diagnostic yield in patients with suspected organic small bowel disease. Seventy-one percent of cases had elevated FL $(r=0.56 ; p=0.01)$. The sensitivity, specificity, PPV, and NPV of FL, using a $7.25 \mu \mathrm{g} / \mathrm{g}$ cutoff, were $71 \%$, $100 \%, 100 \%$, and $83 \%$, respectively [51].

More recently, a study was primarily addressed to evaluate the accuracy of FL in 68 patients with suspected CD. The authors reported that the FL concentration of 1.05 $\mathrm{mg} / \mathrm{kg}$ predicted lesions with sensitivity, specificity, PPV, and NPV of $73 \%, 65 \%, 50 \%$, and $84 \%$. However, the difference of FL values between normal and abnormal CE findings was only borderline significant $(p=0.051)$ [52].

S100A12 was not effective in detecting ileal CD, diagnosed with CE in 84 patients (cutoff $0.06 \mu \mathrm{g} / \mathrm{g}$; sensitivity $59 \%$ and specificity $66 \%$ ). In this study, S100A12, as well as FC, did not correlate with the HBI or CE activity score [53]. Similar results have been recently reported in a small series of patients [43]. Thus, at present, available data are not strong enough to support the use of other fecal markers instead of CE in small bowel CD (Table 2).

\section{Stool Markers and Response to Treatment}

The primary aim of the treatment in CD is to induce and maintain clinical and endoscopic remission and reduce hospitalization rates, disease complications, and surgery [54]. A noninvasive marker of disease activity represents the ideal alternative to multiple endoscopic examinations to drive therapeutic strategies. 
Table 2. Fecal markers and assessment of disease activity in $C D$, according to endoscopic scores

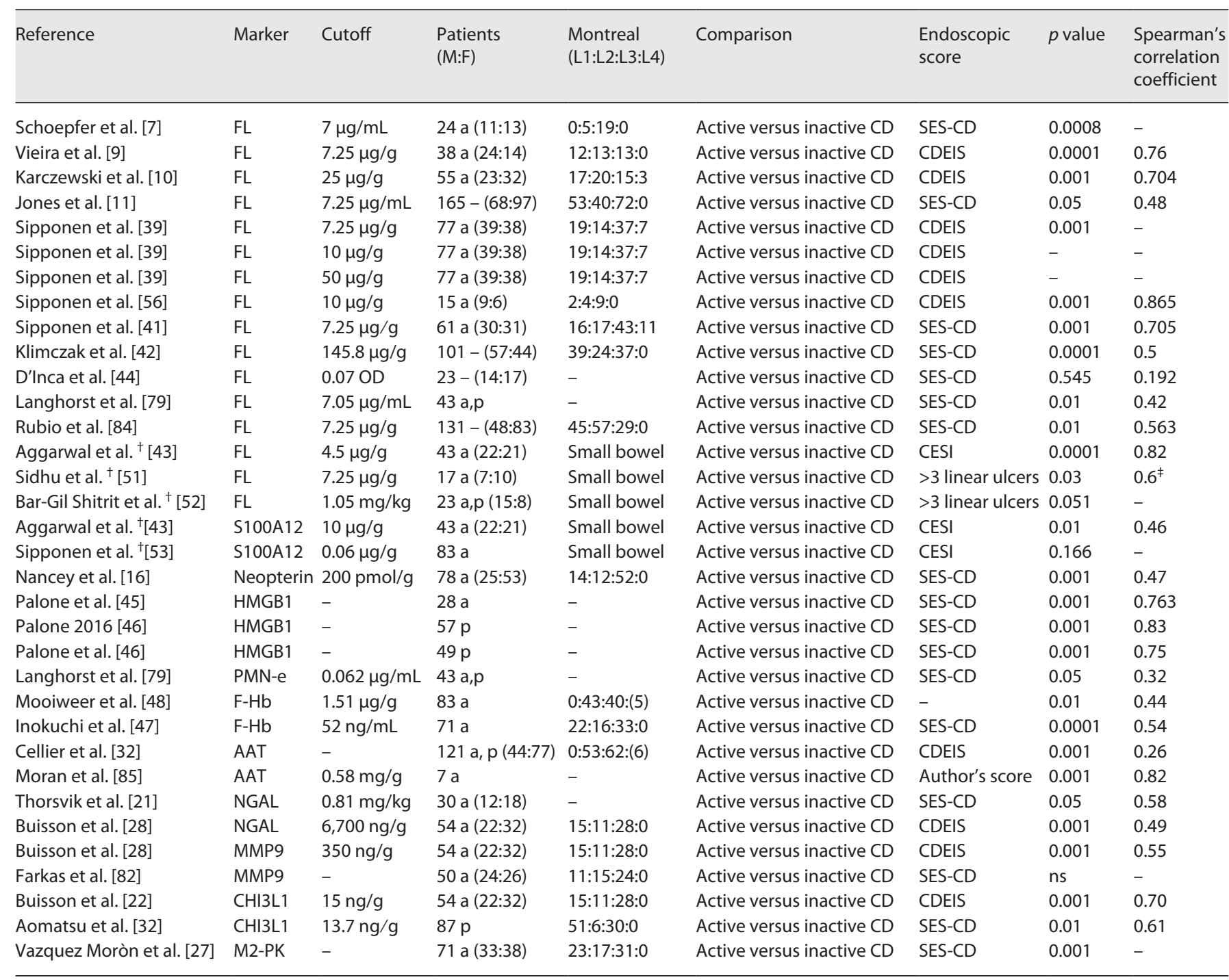

FL, fecal lactoferrin; HMGB1, high mobility group box 1; PMN-e, polymorphonuclear neutrophil elastase; F-Hb, fecal hemoglobin; AAT, alpha 1-antitrypsin; NGAL, neutrophil gelatinase-associated lipocalin; MMP9, matrix metalloproteinase 9; CHI3L1, chitinase 3-like-1; M2-PK, M2-pyruvate kinase; a, adult patients; p, pediatric patients; CDEIS, Crohn's Disease Endoscopic Index of Severity; SES-CD, simple endoscopic score for Crohn's disease; CESI, capsule endoscopy scoring index; ns, nonsignificant; -, not reported; CD, Crohn's disease; CE, capsule endoscopy. ${ }^{\dagger}$ Capsule endoscopy. ${ }^{\ddagger}$ Kendall-Tau correlation. When expressed in brackets, the L4 behavior describes a concomitant involvement of the upper $\mathrm{Gl}$, not isolated upper $\mathrm{Gl}$ disease.

Buderus et al. [55] first described the use of FL in monitoring response to therapy, showing that FL levels paralleled clinical assessment and PCDAI in 5 pediatric patients treated with infliximab. A reduction in FL levels was confirmed in 2 small cohorts of patients effectively treated with anti-TNFa [56], steroids, mesalamine, or thiopurines [57]. A significant decrease from baseline FL levels was reported after 3 and 12 months of therapy in patients treated with anti-TNFa $(p<0.05)$, in parallel to CDAI and SES-CD $(p<0.05)$ [58].
S100A12 performed poorly at 14 weeks (AUC 0.70 ) as compared to FC (AUC 0.87), in discriminating between patients who remained in remission from those who experience a loss of response within a year during anti-TNFa [59]. FC and MPO were similarly effective, in predicting a complete response after 8 weeks of treatment in $11 \mathrm{CD}$ patients $(r=0.936 ; p<0.01)$, with PPV of 12 (95\% CI, 2-53) and an NPV of 100 (95\% CI, 19-100.5). In the same study, FC also correlated with EPX $(r=0.854, p<0.01)$ with PPV of 14 (95\% CI, 3-58) and NPV of 100 (95\% CI, 30-100) [60]. 
Table 3. Fecal markers and response to treatment or prediction of relapse in CD

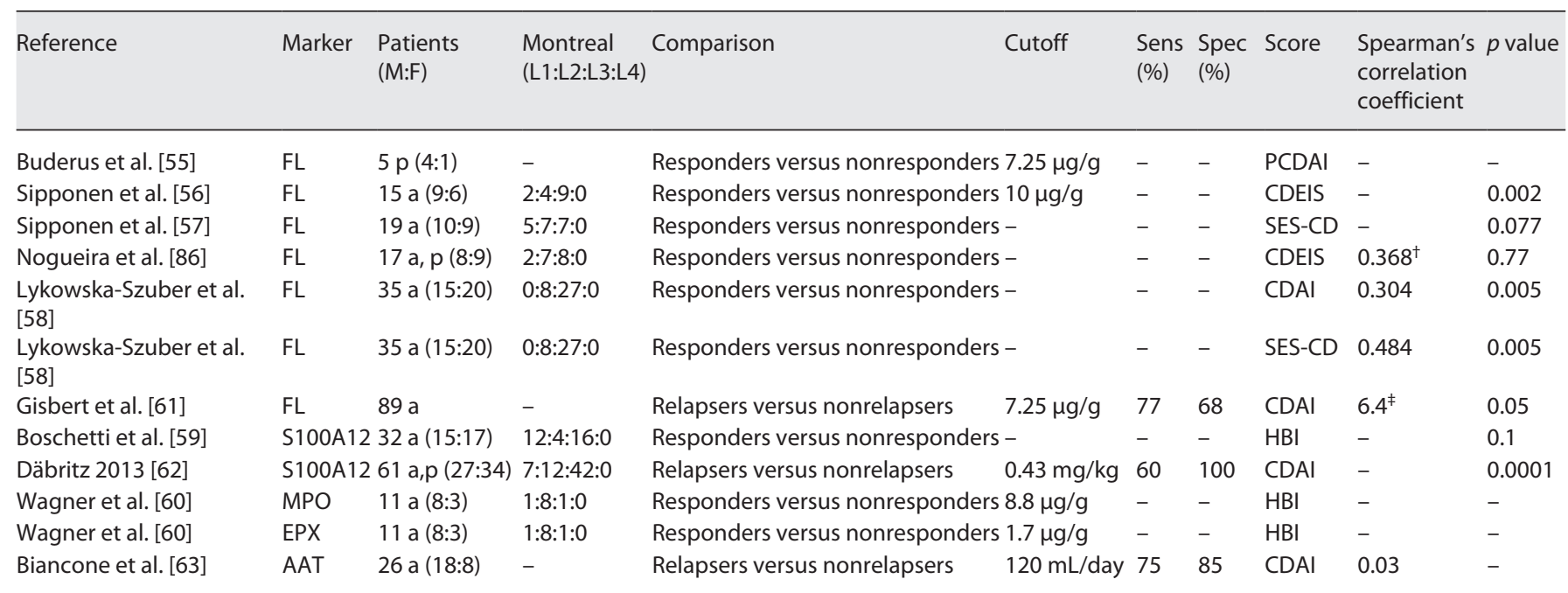

FL, fecal lactoferrin; AAT, alpha1-antitrypsin; MPO, myeloperoxidase; EPX, eosinophil protein $\mathrm{X}$;-, not reported; a, adult patients; p, pediatric patients; PCDAI, Pediatric Crohn's Disease Activity Index; CDAl, Crohn's Disease Activity Index; HBI, Harvey-Bradshaw Index; CDEIS, Crohn's Disease Endoscopic Index of Severity; SES-CD, simple endoscopic score for Crohn's disease; CD, Crohn's disease. ${ }^{\dagger}$ Pearson's correlation coefficient. ${ }^{\ddagger} X^{2}$ test.

It may be concluded that FL, but not other markers, is a reasonably good surrogate marker of response to therapy in CD (Table 3). The low number of studies and the small number of enrolled patients however prompt further supporting evidence.

\section{Stool Markers and Prediction of Relapse}

CD relapses are hardly predictable; thus, identifying high-risk patients would help the physician in targeting therapy. In this respect, due to the lack of hard evidence, no marker can at present replace FC.

A single study on FL carried out in a cohort of 163 IBD patients in clinical remission indicates that the risk of relapse at 3 months of follow-up is higher in patients with increased FL levels (25\% vs. $10 \%$; $p<0.05)$ [61]. Using a $7.25 \mu \mathrm{g} / \mathrm{g}$ cutoff, the sensitivity and specificity to predict relapse in the $89 \mathrm{CD}$ patients were $62 \%$ and $65 \%$, respectively, with an area under the ROC curve of 0.77 . In keeping with FC data, optimal sensitivity (100\%) was observed in the colonic disease $[1,60]$. The qualitative assessment of results however represents the main limitation of this study [61].

S100A12 has also been investigated as a potential biomarker of relapse in a mixed cohort, including adults and children. Fecal S100A12 levels were significantly higher in relapsers than in nonrelapsers. A significant and progressive rise of levels preceded relapse [62].

In a prospective longitudinal study including 26 patients with inactive ileal CD, AAT fecal levels at baseline were significantly raised in patients who experienced flare-up within the next 6 months (cutoff $120 \mathrm{~mL} /$ day; $p$ $=0.03 ; 75 \%$ sensitivity and $85 \%$ specificity, $50 \% \mathrm{PPV}$ and $94 \% \mathrm{NPV}$ ) [63]. All the reported studies were carried out prospectively, but the follow-up was usually short. All considered biomarkers other than FC seem to be of some use in identifying patients at high risk for endoscopic relapse (Table 3), but again more trials are needed.

\section{Stool Markers and Post-Operative Recurrence}

POR is common in CD patients. Prevention strategies and modulation of therapeutic intervention are mainly based on endoscopic examination at 6-12 months following surgery as clinical symptoms are unreliable, and systemic markers of inflammation have low sensitivity. A performing, noninvasive biological marker could be useful to predict early recurrence, limiting invasive procedures.

Few, but promising, studies have been carried out on the role of FL in the postoperative setting. A significant increase of FL levels was reported in 2 cohorts of patients 
Table 4. Fecal markers and prediction of POR of CD according to Rutgeerts' score

\begin{tabular}{|c|c|c|c|c|c|c|c|c|}
\hline Reference & Marker & Patients (M:F) & Resection & Comparison & Cutoff & Sens (\%) & Spec (\%) & $p$ value \\
\hline Scarpa et al. [64] & $\mathrm{FL}$ & 63 a,p (41:22) & Ileocolonic & Recurrence versus remission & - & - & - & 0.04 \\
\hline Lamb et al. [65] & $\mathrm{FL}$ & $104 \mathrm{a}(43: 61)$ & Ileocolonic & Recurrence versus remission & $7 \mu \mathrm{g} / \mathrm{mL}$ & - & - & 0.730 \\
\hline Yamamoto et al. [67] & $\mathrm{FL}$ & 20 a $(12: 8)$ & Ileocolonic & Recurrence versus remission & $125 \mu \mathrm{g} / \mathrm{g}$ & 70 & 60 & 0.038 \\
\hline Wright et al. [70] & $\mathrm{FL}$ & 135 a (59:76) & Ileal or ileocolonic & Recurrence versus remission & $3.4 \mu \mathrm{g} / \mathrm{g}$ & 70 & 68 & 0.008 \\
\hline Lopes et al. [68] & $\mathrm{FL}$ & 99 a (47:52) & Ileocolonic & Recurrence versus remission & $7.25 \mu \mathrm{g} / \mathrm{g}$ & 55 & 79 & 0.05 \\
\hline Wright et al. [70] & $\mathrm{S} 100 \mathrm{~A} 12$ & 135 a (59:76) & Ileal or ileocolonic & Recurrence versus remission & $10.5 \mathrm{mg} / \mathrm{g}$ & 91 & 12 & 0.937 \\
\hline Boirivant et al. [71] & AAT & $11 \mathrm{a}$ & Ileocolonic & Recurrence versus remission & - & - & - & 0.01 \\
\hline
\end{tabular}

FL, fecal lactoferrin; AAT, alpha1-antitrypsin; -, not reported; a, adult patients; p, pediatric patients; CD, Crohn's disease; POR, postoperative recurrence.

with clinical recurrence after ileocolonic resection [64, 65]. FL significantly correlated with IL-6 $(r=0.431 ; p=$ $0.025)$ and C-reactive protein $(r=0.507 ; p=0.007)$ in patients with subclinical intestinal inflammation [66]. However, a significant correlation with CDAI was not found $(r=0.103 ; p=0.615)$.

In a prospective study including $20 \mathrm{CD}$ patients, both FC and FL levels were significantly higher in patients with clinical recurrence than those in remission $(p=0.0007$ and $p=0.025$, respectively) predicting the clinical and endoscopic recurrence after ileocolonic resection [67]. A cutoff value of $170 \mu \mathrm{g} / \mathrm{g}$ for FC had a sensitivity of $83 \%$ (95\% CI, $54-113 \%)$ and a specificity of $93 \%$ (95\% CI, 79$106 \%$ ) to predict clinical recurrence, while a cutoff of 140 $\mu \mathrm{g} / \mathrm{g}$ for FL had a sensitivity of $67 \%$ (95\% CI, 29-104\%) and a specificity of $71 \%$ (95\% CI, $48-95 \%)$. The cumulative recurrence rate was higher in patients with elevated FL levels $(\geq 140 \mu \mathrm{g} / \mathrm{g})$ than in those with lower values $(<140 \mu \mathrm{g} / \mathrm{g})$, but statistical significance was not reached $(p=0.077)$. Both FC and FL levels positively correlated with postoperative endoscopic scores in the neoterminal ileum ( $p=0.0001$ and $p=0.038$, respectively). A cutoff value of $125 \mu \mathrm{g} / \mathrm{g}$ for FL detected endoscopic recurrence with a sensitivity of $70 \%$ (95\% CI, $42-98 \%)$, a specificity of $60 \%$ (95\% CI, 30-90\%), a PPV of $64 \%$ (95\% CI, 35$92 \%)$, an NPV of $67 \%$ (95\% CI, 36-97\%), and a diagnostic accuracy of 65\% (95\% CI, 44-86\%) [67].

Much lower FL cutoff values $(7.25 \mu \mathrm{g} / \mathrm{g}$ and $5.6 \mu \mathrm{g} / \mathrm{g})$ showed comparable or better correlations with endoscopic recurrence (sensitivity $85 \%$, specificity $74 \%$, PPV 64\%, NPV 90\%) [68] and asymptomatic anastomotic strictures (sensitivity $77.3 \%$, specificity $69.2 \%$, PPV 68\%, NPV 78.4\%) [69] in larger series. This suggests that FL may represent an acceptably good noninvasive marker in the postoperative setting but, again, large multicenter prospective trials are needed to confirm preliminary findings and identify appropriate cutoff values (Table 4 ).

Wright et al. [70] evaluated in a prospective study of 135 adult $\mathrm{CD}$ patients the accuracy of FC, FL, and fecal S1000A12 for the detection of postoperative endoscopic CD recurrence. At 6 months postoperatively, all fecal markers decreased in patients in remission but were higher in recurrent disease. FC $>135 \mu \mathrm{g} / \mathrm{g}, \mathrm{FL}>3.4 \mu \mathrm{g} / \mathrm{g}$, and fecal S1000A12 > 10.5 suggested endoscopic recurrence, with a sensitivity, specificity, and NPV of $0.87,0.66$, and $91 \% ; 0.70,0.68$, and $81 \% ; 0.91,0.12$, and $71 \%$, respectively. FC and FL, but not fecal S1000A12, significantly correlated with the presence and severity of endoscopic recurrence [70]. The levels of fecal AAT at 6 and 12 months after terminal ileum resection were increased in patients presenting with clinical recurrence, as compared to those who did not $(p<0.01)$ [71].

\section{Discussion}

Surrogate biomarkers of intestinal inflammation are clinically attractive in daily medical practice, providing a noninvasive tool for selecting CD patients who most require invasive/expensive examination. Fecal biomarkers are relatively inexpensive and may be repeated during the follow-up of patients, to evaluate the effectiveness of a therapy or to detect the loss of response in an early stage, before the occurrence of symptoms. FC is thus used more and more often in clinical practice.

Many issues concerning the optimal use of FC, including ideal time interval and threshold values, variability among different kits, and low accuracy in detecting small bowel CD, are still open [1]. Hence, there is a need to ex- 
plore the performance of alternative fecal biomarkers that could offer advantages over FC.

The most widely studied fecal marker, besides FC, is FL. This protein, similar to other fecal biomarkers used in $\operatorname{IBD}[3,72]$, is a major component of the secondary granules of neutrophils $[5,73]$ and parallels the number of neutrophils during intestinal inflammation [74]. In contrast to FC, also present in the cytosol of monocytes, FL is not produced by other hematopoietic cells [75]. Conversely, FL is secreted to some extent by mucosal epithelial cells, which represent a minor, noninflammatory source of this protein [73]. As FL mainly depends upon neutrophil-mediated inflammation, it reflects the same biological mechanisms as FC. FC and FL are both markers of acute inflammation, and that may be an explanation for the similar performance of these proteins. Moreover, resulting mostly from neutrophils, FL does not allow the investigation of different aspects of IBD-related lesions, such as epithelial damage. Also in this respect, FL does not offer significant advantages over FC.

Both FC and FL are resistant to proteolysis in the gut lumen and are remarkably stable within feces at room temperature, up to 7 days [76, 77]. Although the stability of FL is slightly shorter than that of FC at room temperature [78], the difference is not relevant as both proteins remain stable long enough to allow a reliable analysis of frozen-thawed samples [76, 77]. Also, the costs of enzyme-linked immunosorbent assay (ELISA) kits are comparable in FL and FC [7].

As for FC, also in the case of FL, it is not possible to identify an accurate cutoff value that could be used throughout all the clinical scenarios. Similarly, due to the heterogeneity of the studies, it is difficult to calculate an average value in the single settings (relapse, recurrence, response to therapy).

However, an advantage of FL versus FC consists in the good agreement on the optimal threshold of FL (7.25 $\mu \mathrm{g} / \mathrm{g})[6,38,51,79]$ to detect clinical or endoscopic activity in CD. Data are more robust compared to FC and represent a clear advantage when the test is performed in different laboratories. Nonetheless, whereas sensitivity is good, specificity widely varies, a problem shared by all the other fecal markers. Details on sensitivity and specificity of differing fecal markers about diagnosis and detection of clinical or endoscopic activity are summarized in online suppl. Table 2. An FL level much higher than $7.25 \mu \mathrm{g} / \mathrm{g}$ indicates intestinal inflammation and suggests the need for further evaluation. However, when the marker is just above this threshold, FL should best be rechecked.

Fecal Markers in Crohn's Disease
A meta-analysis, moreover, suggests that the accuracy of FL in the detection of endoscopic activity is comparable to that of FC (cut-off $7.25 \mu \mathrm{g} / \mathrm{mL}$ vs. $50 \mu \mathrm{g} / \mathrm{g}$; pooled sensitivity and specificity of 0.82 [ $95 \%$ CI, $0.73-0.88$ ] and 0.79 [95\% CI, $0.62-0.89$ ] vs. 0.87 [95\% CI, $0.82-0.91]$ and 0.67 [95\% CI, 0.58-0.75]) [40]. Considering disease location, the performance does not favor FL over FC in small bowel involvement, as short actively inflamed segments may not modify FL. One single study reported a better correlation of FL with CDEIS, compared to FC in patients with exclusively ileal disease $(r=0.678 ; r=0.316$, respectively) [39]. The correlation levels ( $r$ values) reported by other authors however were far from optimal (Table 2). Again, FL performs much better in colonic than in small bowel disease [41], as well as in ulcerative colitis than in CD [80]. No studies specifically assessed the performance of FL in CD penetrating, structuring, and inflammatory clinical behavior.

Although most FL ELISA kits use the same cutoff value, rapid qualitative tests are also available, characterized by lower accuracy and reproducibility. This limitation is balanced by the lower cost [7]. Rapid qualitative analysis is not widely used and is restricted only to ruling out intestinal inflammation. However, the different results obtained using ELISA kits must be taken into account when comparing different studies.

Data on fecal markers other than FL are scarce and mainly deriving from small and mixed IBD cohorts (online suppl. Table 3). No hard conclusion may thus be drawn on their performance in CD. As far as FL is concerned, available evidence suggests that it represents a manageable alternative to $\mathrm{FC}$, although performance and costs are similar. More extensive investigations are required to better define in which clinical settings FL could offer, if any, potential advantage and usefulness.

\section{Acknowledgments}

Except the authors, no other individuals or organizations made substantive contributions to the manuscript.

\section{Statement of Ethics}

Being a review, the study is exempt from ethical committee approval/informed consent. 


\section{Conflict of Interest Statement}

The authors have no conflicts of interest to declare.

\section{Funding Sources}

The authors received no specific funding for this work from any agency in the public, commercial, or not-for-profit sectors.

\section{Author Contributions}

F.V., M.D.R., G.S., and M.V. performed the literature review, wrote the manuscript, and prepared the figures; A.V. and G.L. reviewed the manuscript and provided critical comments; G.L. suggested the topic of the review and supervised, wrote, and critically reviewed the manuscript. All authors have read and agreed to the published version of the manuscript.

\section{Data Availability Statement}

All data generated or analyzed during this study are included in this article and its online supplementary material files.

\section{References}

1 Vernia F, Di Ruscio M, Stefanelli G, Viscido A, Frieri G, Latella G. Is fecal calprotectin an accurate marker in the management of Crohn's disease? J Gastroenterol Hepatol. 2020;35:390-400.

2 Dai C, Jiang M, Sun MJ, Cao Q. Fecal lactoferrin for assessment of inflammatory bowel disease activity: a systematic review and metaanalysis. J Clin Gastroenterol. 2020;54(6): 545-53.

3 Di Ruscio M, Vernia F, Ciccone A, Frieri G, Latella G. Surrogate fecal biomarkers in inflammatory bowel disease: rivals or complementary tools of fecal calprotectin? Inflamm Bowel Dis. 2017;24:78-92.

4 Falvey JD, Hoskin T, Meijer B, Ashcroft A, Walmsley R, Day AS, et al. Disease activity assessment in IBD: clinical indices and biomarkers fail to predict endoscopic remission. Inflamm Bowel Dis. 2015;21:824-31.

5 Kane SV, Sandborn WJ, Rufo PA, Zholudev $\mathrm{A}$, Boone J, Lyerly $\mathrm{D}$, et al. Fecal lactoferrin is a sensitive and specific marker in identifying intestinal inflammation. Am J Gastroenterol. 2003;98:1309-14

6 Walker TR, Land ML, Kartashov A, Saslowsky TM, Lyerly DM, Boone JH, et al. Fecal lactoferrin is a sensitive and specific marker of disease activity in children and young adults with inflammatory bowel disease. J Pediatr Gastroenterol Nutr. 2007;44:414-22.

7 Schoepfer AM, Trummler M, Seeholzer P, Criblez DH, Seibold F. Accuracy of four fecal assays in the diagnosis of colitis. Dis Colon Rectum. 2007;50:1697-706.

8 Dai J, Liu WZ, Zhao YP, Hu YB, Ge ZZ. Relationship between fecal lactoferrin and inflammatory bowel disease. Scand J Gastroenterol. 2007;42:1440-4.

9 Vieira A, Fang CB, Rolim EG, Klug WA, Steinwurz F, Rossini LG, et al. Inflammatory bowel disease activity assessed by fecal calprotectin and lactoferrin: correlation with laboratory parameters, clinical, endoscopic and histological indexes. BMC Res Notes. 2009;2: 221.
10 Karczewski J, Swora-Cwynar E, Rzymski P, Poniedziałek B, Adamski Z. Selected biologic markers of inflammation and activity of Crohn's disease. Autoimmunity. 2015;48: $318-27$.

11 Jones J, Loftus EV Jr, Panaccione R, Chen LS, Peterson S, McConnell J, et al. Relationships between disease activity and serum and fecal biomarkers in patients with Crohn's disease. Clin Gastroenterol Hepatol. 2008;6:1218-24.

12 de Jong NS, Leach ST, Day AS. Fecal S100A12: a novel noninvasive marker in children with Crohn's disease. Inflamm Bowel Dis. 2006;12: 566-72.

13 Sidler MA, Leach ST, Day AS. Fecal S100A12 and fecal calprotectin as noninvasive markers for inflammatory bowel disease in children. Inflamm Bowel Dis. 2008;14:359-66.

14 Kaiser T, Langhorst J, Wittkowski H, Becker K, Friedrich AW, Rueffer A, et al. Faecal S100A12 as a non-invasive marker distinguishing inflammatory bowel disease from irritable bowel syndrome. Gut. 2007;56:170613.

15 Husain N, Tokoro K, Popov JM, Naides SJ, Kwasny MJ, Buchman AL. Neopterin concentration as an index of disease activity in Crohn's disease and ulcerative colitis. J Clin Gastroenterol. 2013;47:246-51.

16 Nancey S, Boschetti G, Moussata D, Cotte E, Peyras J, Cuerq C, et al. Neopterin is a novel reliable fecal marker as accurate as calprotectin for predicting endoscopic disease activity in patients with inflammatory bowel diseases. Inflamm Bowel Dis. 2013;19:1043-52.

17 Adeyemi EO, Hodgson HJ. Faecal elastase reflects disease activity in active ulcerative colitis. Scand J Gastroenterol. 1992;27:139-42.

18 Saitoh O, Sugi K, Matsuse R, Uchida K, Matsumoto $\mathrm{H}$, Nakagawa $\mathrm{K}$, et al. The forms and the levels of fecal PMN-elastase in patients with colorectal diseases. Am J Gastroenterol. 1995; 90:388-93.

19 Sugi K, Saitoh O, Hirata I, Katsu K. Fecal lactoferrin as a marker for disease activity in inflammatory bowel disease: comparison with other neutrophil-derived proteins. Am J Gastroenterol. 1996;91:927-34.

20 Andus T, Gross V, Caesar I, Krumm D, Hosp $\mathrm{J}$, Gerok W, et al. PMN-elastase in assessment of patients with inflammatory bowel disease. Dig Dis Sci. 1993;38:1638-44.

21 Thorsvik S, Damås JK, Granlund AV, Flo TH Bergh K, Østvik AE, et al. Fecal neutrophil gelatinase-associated lipocalin as a biomarker for inflammatory bowel disease. J Gastroenterol Hepatol. 2017;32:128-35.

22 Buisson A, Vazeille E, Minet-Quinard R, Goutte M, Bouvier D, Goutorbe F, et al. Faecal chitinase 3 -like 1 is a reliable marker as accurate as faecal calprotectin in detecting endoscopic activity in adult patients with inflammatory bowel diseases. Aliment Pharmacol Ther. 2016;43:1069-79.

23 van der Sluys Veer A, Brouwer J, Biemond I, Bohbouth GE, Verspaget HW, Lamers CB. Fecal lysozyme in assessment of disease activity in inflammatory bowel disease. Dig Dis Sci. 1998;43:590-5.

24 Chung-Faye G, Hayee B, Maestranzi S, Donaldson N, Forgacs I, Sherwood R. Fecal M2pyruvate kinase (M2-PK): a novel marker of intestinal inflammation. Inflamm Bowel Dis. 2007;13:1374-8.

25 Peterson CG, Eklund E, Taha Y, Raab Y, Carlson M. A new method for the quantification of neutrophil and eosinophil cationic proteins in feces: establishment of normal levels and clinical application in patients with inflammatory bowel disease. Am J Gastroenterol. 2002;97:1755-62.

26 Saitoh O, Kojima K, Sugi K, Matsuse R, Uchida K, Tabata K, et al. Fecal eosinophil granulederived proteins reflect disease activity in inflammatory bowel disease. Am J Gastroenterol. 1999;94:3513-20.

27 Vázquez Morón JM, Pallarés Manrique $\mathrm{H}$, Machancoses FH, Ramos Lora M, Ruiz Frutos C. Accurate cut-offs for predicting endoscopic activity and mucosal healing in Crohn's disease with fecal calprotectin. Rev Esp Enferm Dig. 2017;109:130-6. 
28 Buisson A, Vazeille E, Minet-Quinard R, Goutte M, Bouvier D, Goutorbe F, et al. Fecal matrix metalloprotease-9 and lipocalin-2 as biomarkers in detecting endoscopic activity in patients with inflammatory bowel diseases. J Clin Gastroenterol. 2018;52(7):e53-62.

29 Czub E, Herzig KH, Szafarska-Popawska A, Kiehne K, Socha P, Woś H, et al. Fecal pyruvate kinase: a potential new marker for intestinal infammation in children with infammatory bowel disease. Scand J Gastroenterol. 2007; $42: 1147-50$

30 Roszak D, Gałęcka M, Cichy W, Szachta P. Determination of faecal inflammatory marker concentration as a noninvasive method of evaluation of pathological activity in children with inflammatory bowel diseases. Adv Med Sci. 2015;60:246-52.

31 Cellier C, Sahmoud T, Froguel E, Adenis A, Belaiche J, Bretagne JF, et al. Correlations between clinical activity, endoscopic severity, and biological parameters in colonic or ileocolonic Crohn's disease. A prospective multicentre study of 121 casesThe Groupe d'Etudes Thérapeutiques des affections inflammatoires digestives. Gut. 1994;35:231-5.

32 Aomatsu T, Imaeda H, Matsumoto K, Kimura E, Yoden A, Tamai H, et al. Faecal chitinase 3-like-1: a novel biomarker of disease activity in paediatric inflammatory bowel disease. Aliment Pharmacol Ther. 2011;34:941-8.

33 Meyers S, Wolke A, Field SP, Feuer EJ, Johnson JW, Janowitz HD. Fecal a1-antitrypsin measurement: an indicator of Crohn's disease activity. Gastroenterology. 1985;89:13-8.

34 Becker K, Berger M, Niederau C, Frieling T Individual fecal alpha 1-antitrypsin excretion reflects clinical activity in Crohn's disease but not in ulcerative colitis. Hepatogastroenterology. 1999;46:2309-14.

35 Herzog D, Delvin E, Seidman E. Fecal a1antitrypsin: a marker of intestinal versus systemic inflammation in pediatric Crohn's disease? Inflamm Bowel Dis. 1996;2:236-43.

36 Day AS, Judd T, Lemberg DA, Leach ST. Fecal M2-PK in children with Crohn's disease: a preliminary report. Dig Dis Sci. 2012;57: 2166-70.

37 Kolho KL, Sipponen T, Valtonen E, Savilahti E. Fecal calprotectin, MMP-9, and human beta-defensin-2 levels in pediatric inflammatory bowel disease. Int J Colorectal Dis. 2014;29: 43-50.

38 Pfefferkorn MD, Boone JH, Nguyen JT, Juliar BE, Davis MA, Parker KK. Utility of fecal lactoferrin in identifying Crohn disease activity in children. J Pediatr Gastroenterol Nutr. 2010;51:425-8.

39 Sipponen T, Savilahti E, Kolho KL, Nuutinen H, Turunen U, Färkkilä M. Crohn's disease activity assessed by fecal calprotectin and lactoferrin: correlation with Crohn's disease activity index and endoscopic findings. Inflamm Bowel Dis. 2008;14:40-6.
40 Mosli MH, Zou G, Garg SK, Feagan SG, MacDonald JK, Chande N, et al. C-reactive protein, fecal calprotectin, and stool lactoferrin for detection of endoscopic activity in symptomatic inflammatory bowel disease patients: a systematic review and meta-analysis. Am J Gastroenterol. 2015;110:802-20.

41 Sipponen T, Kärkkäinen P, Savilahti E, Kolho KL, Nuutinen H, Turunen U, et al. Correlation of faecal calprotectin and lactoferrin with an endoscopic score for Crohn's disease and histological findings. Aliment Pharmacol Ther. 2008;28:1221-9.

42 Klimczak K, Lykowska-Szuber L, Eder P, Krela-Kazmierczak I, Stawczyk-Eder K, Szymczak A, et al. The diagnostic usefulness of fecal lactoferrin in the assessment of Crohn's disease activity. Eur J Intern Med. 2015;26:6237.

43 Aggarwal V, Day AS, Connor S, Leach ST, Brown G, Singh R, et al. Role of capsule endoscopy and fecal biomarkers in small-bowel Crohn's disease to assess remission and predict relapse. Gastrointest Endosc. 2017;86: $1070-8$.

44 D'Incà R, Dal Pont E, Di Leo V, Ferronato A, Fries W, Vettorato MG, et al. Calprotectin and lactoferrin in the assessment of intestinal inflammation and organic disease. Int J Colorectal Dis. 2007;22:429-37.

45 Palone F, Vitali R, Cucchiara S, Pierdomenico M, Negroni A, Aloi M, et al. Role of HMGB1 as a suitable biomarker of subclinical intestinal inflammation and mucosal healing in patients with inflammatory bowel disease. In flamm Bowel Dis. 2014;20:1448-57.

46 Palone F, Vitali R, Cucchiara S, Mennini M, Armuzzi A, Pugliese D, et al. Fecal HMGB1 reveals microscopic inflammation in adult and pediatric patients with inflammatory bowel disease in clinical and endoscopic remission. Inflamm Bowel Dis. 2016;22:288693.

47 Inokuchi T, Kato J, Hiraoka S, Takashima S, Nakarai A, Takei D, et al. Fecal immunochemical test versus fecal calprotectin for prediction of mucosal healing in Crohn's disease. Inflamm Bowel Dis. 2016;22(5):1078-85.

48 Mooiweer E, Fidder HH, Siersema PD, Lahei RJ, Oldenburg B. Fecal hemoglobin and calprotectin are equally effective in identifying patients with inflammatory bowel disease with active endoscopic inflammation. Inflamm Bowel Dis. 2014;20:307-14.

49 Molinié F, Gower-Rousseau C, Yzet T, Merle V, Grandbastien B, Marti R, et al. Opposite evolution in incidence of Crohn's disease and ulcerative colitis in Northern France (19881999). Gut. 2004;53:843-8.

50 Dionisio PM, Gurudu SR, Leighton JA, Leontiadis GI, Fleischer DE, Hara AK, et al. Capsule endoscopy has a significantly higher diagnostic yield in patients with suspected and established small-bowel Crohn's disease: a meta-analysis. Am J Gastroenterol. 2010;105: $1240-9$.
51 Sidhu R, Sanders DS, Wilson P, Foye L, Morley S, McAlindon ME. Faecal lactoferrin, capsule endoscopy and Crohn's disease. Is there a three way relationship? A pilot study. J Gastrointestin Liver Dis. 2010;19:257-60.

52 Bar-Gil Shitrit A, Koslowsky B, Livovsky DM, Shitrit D, Paz K, Adar T, et al. A prospective study of fecal calprotectin and lactoferrin as predictors of small bowel Crohn's disease in patients undergoing capsule endoscopy. Scand J Gastroenterol. 2017;52:328-33.

53 Sipponen T, Haapamäki J, Savilahti E, Alfthan $\mathrm{H}$, Hämäläinen $\mathrm{E}$, Rautiainen $\mathrm{H}$, et al. Fecal calprotectin and S100A12 have low utility in prediction of small bowel Crohn's disease detected by wireless capsule endoscopy. Scand J Gastroenterol. 2012;47:778-84.

54 D’Haens GR, Fedorak R, Lémann M, Feagan BG, Kamm MA, Cosnes J, et al. Endpoints for clinical trials evaluating disease modification and structural damage in adults with Crohn's disease. Inflamm Bowel Dis. 2009;15:1599-604.

55 Buderus S, Boone J, Lyerly D, Lentze MJ. Fecal lactoferrin: a new parameter to monitor infliximab therapy. Dig Dis Sci. 2004;49:1036-9.

56 Sipponen T, Savilahti E, Kärkkäinen P, Kolho KL, Nuutinen $\mathrm{H}$, Turunen U, et al. Fecal calprotectin, lactoferrin, and endoscopic disease activity in monitoring anti-TNF-alpha therapy for Crohn's disease. Inflamm Bowel Dis. 2008; 14:1392-8.

57 Sipponen T, Björkesten CG, Färkkilä M, Nuutinen H, Savilahti E, Kolho KL. Faecal calprotectin and lactoferrin are reliable surrogate markers of endoscopic response during Crohn's disease treatment. Scand J Gastroenterol. 2010;45:325-31.

58 Łykowska-Szuber L, Klimczak K, Eder P, Krela-Kaźmierczak I, Stawczyk-Eder K, Michalak M, et al. Diagnostic importance of faecal markers in long-term monitoring of antiTNF- $\alpha$ therapy in primary responders with Crohn's disease. Prz Gastroenterol. 2016; 11(4):232-8.

59 Boschetti G, Garnero P, Moussata D, Cuerq C, Préaudat C, Duclaux-Loras R, et al. Accuracies of serum and fecal $\mathrm{S} 100$ proteins (calprotectin and calgranulin $\mathrm{C}$ ) to predict the response to TNF antagonists in patients with Crohn's disease. Inflamm Bowel Dis. 2015;21: 331-6.

60 Wagner M, Peterson CG, Ridefelt P, Sangfelt $\mathrm{P}$, Carlson M. Fecal markers of inflammation used as surrogate markers for treatment outcome in relapsing inflammatory bowel disease. World J Gastroenterol. 2008;14:5584-8.

61 Gisbert JP, Bermejo F, Pérez-Calle JL, Taxonera C, Vera I, McNicholl AG, et al. Fecal calprotectin and lactoferrin for the prediction of inflammatory bowel disease relapse. Inflamm Bowel Dis. 2009;15:1190-8.

62 Däbritz J, Langhorst J, Lügering A, Heidemann J, Mohr M, Wittkowski H, et al. Improving relapse prediction in inflammatory bowel disease by neutrophil-derived S100A12. Inflamm Bowel Dis. 2013;19:1130-8. 
63 Biancone L, Fantini M, Tosti C, Bozzi R, Vavassori P, Pallone F. Fecal alpha 1-antitrypsin clearance as a marker of clinical relapse in patients with Crohn's disease of the distal ileum. Eur J Gastroenterol Hepatol. 2003;15:261-6.

64 Scarpa M, D'Incà R, Basso D, Ruffolo C, Polese L, Bertin E, et al. Fecal lactoferrin and calprotectin after ileocolonic resection for Crohn's disease. Dis Colon Rectum. 2007;50: 861-9.

65 Lamb CA, Mohiuddin MK, Gicquel J, Neely D, Bergin FG, Hanson JM, et al. Faecal calprotectin or lactoferrin can identify postoperative recurrence in Crohn's disease. Br J Surg. 2009;96:663-74.

66 Ruffolo C, Scarpa M, Faggian D, Basso D, D'Incà R, Plebani M, et al. Subclinical intestinal inflammation in patients with Crohn's disease following bowel resection: a smoldering fire. J Gastrointest Surg. 2010;14:24-31.

67 Yamamoto T, Shiraki M, Bamba T, Umegae S, Matsumoto K. Faecal calprotectin and lactoferrin as markers for monitoring disease activity and predicting clinical recurrence in patients with Crohn's disease after ileocolonic resection: a prospective pilot study. United Eur Gastroenterol J. 2013;1:368-74.

68 Lopes S, Andrade P, Afonso J, Rodrigues-Pinto E, Dias CC, Macedo G, et al. Correlation between calprotectin and modified Rutgeerts score. Inflamm Bowel Dis. 2016;22:2173-81.

69 Lopes S, Andrade P, Rodrigues-Pinto E, Afonso J, Macedo G, Magro F. Fecal marker levels as predictors of need for endoscopic balloon dilation in Crohn's disease patients with anastomotic strictures. World J Gastroenterol. 2017;23:6482-90.

70 Wright EK, Kamm MA, De Cruz P, Hamilton AL, Ritchie KJ, Keenan JI, et al. Comparison of fecal inflammatory markers in Crohn's disease. Inflamm Bowel Dis. 2016;22:1086-94.
71 Boirivant M, Pallone F, Ciaco A, Leoni M, Fais S, Torsoli A. Usefulness of fecal alpha 1 -antitrypsin clearance and fecal concentration as early indicator of postoperative asymptomatic recurrence in Crohn's disease. Dig Dis Sci. 1991;36:347-52.

72 Däbritz J, Musci J, Foell D. Diagnostic utility of faecal biomarkers in patients with irritable bowel syndrome. World J Gastroenterol. 2014;20:363-75.

73 Levay PF, Viljoen M. Lactoferrin: a general review. Haematologica. 1995;80:252-67.

74 Desai D, Faubion WA, Sandborn WJ. Review article: biological activity markers in inflammatory bowel disease. Aliment Pharmacol Ther. 2007;25:247-55.

75 Angriman I, Scarpa M, D'Incà R, Basso D, Ruffolo C, Polese L, et al. Enzymes in feces: useful markers of chronic inflammatory bowel disease. Clin Chim Acta. 2007;381:63-8.

76 Røseth AG, Fagerhol MK, Aadland E, Schjønsby H. Assessment of the neutrophil dominating protein calprotectin in feces. A methodologic study. Scand J Gastroenterol. 1992;27:793-8.

77 Guerrant RL, Araujo V, Soares E, Kotloff K, Lima AA, Cooper WH, et al. Measurement of fecal lactoferrin as a marker of fecal leukocytes. J Clin Microbiol. 1992;30:1238-42.

78 Silberer H, Küppers B, Mickisch O, Baniewicz W, Drescher M, Traber L, et al. Fecal leukocyte proteins in inflammatory bowel disease and irritable bowel syndrome. Clin Lab. 2005; 51:117-26.

79 Langhorst J, Elsenbruch S, Koelzer J, Rueffer A, Michalsen A, Dobos GJ. Noninvasive markers in the assessment of intestinal inflammation in inflammatory bowel diseases: performance of fecal lactoferrin, calprotectin, and PMN-elastase, CRP, and clinical indices. Am J Gastroenterol. 2008;103:162-9.
80 Wang Y, Pei F, Wang X, Sun Z, Hu C, Dou H. Diagnostic accuracy of fecal lactoferrin for inflammatory bowel disease: a meta-analysis. Int J Clin Exp Pathol. 2015;8:12319-32.

81 Vitali R, Stronati L, Negroni A, Di Nardo G, Pierdomenico M, del Giudice E, et al. Fecal HMGB1 is a novel marker of intestinal mucosal inflammation in pediatric inflammatory bowel disease. Am J Gastroenterol. 2011;106: 2029-40.

82 Farkas K, Saródi Z, Bálint A, Földesi I, Tiszlavicz L, Szücs M, et al. The diagnostic value of a new fecal marker, matrix metalloprotease- 9 , in different types of inflammatory bowel diseases. J Crohns Colitis. 2015;9:2317.

83 Czub E, Nowak JK, Szaflarska-Poplawska A, Grzybowska-Chlebowczyk U, Landowski P, Moczko J, et al. Comparison of fecal pyruvate kinase isoform M2 and calprotectin in assessment of pediatric inflammatory bowel disease severity and activity. Acta Biochim Pol. 2014; 61:99-102.

84 Rubio MG, Amo-Mensah K, Gray JM, Nguyen VQ, Nakat S, Grider D, et al. Fecal lactoferrin accurately reflects mucosal inflammation in inflammatory bowel disease. World J Gastrointest Pathophysiol. 2019;10:54-63.

85 Moran A, Jones A, Asquith P. Laboratory markers of colonoscopic activity in ulcerative colitis and Crohn's colitis. Scand J Gastroenterol. 1995;30:356-60.

86 Nogueira IM, Miszputen SJ, Ambrogini O Jr, Artigiani-Neto R, Carvente CT, Zanon MI. Assessment of the response of patients with Crohn's disease to biological therapy using new non-invasive markers: lactoferrin and calprotectin. Arq Gastroenterol. 2013;50: 130-7. 